\title{
The role of angiopoietin-2 in nucleus pulposus cells during human intervertebral disc degeneration
}

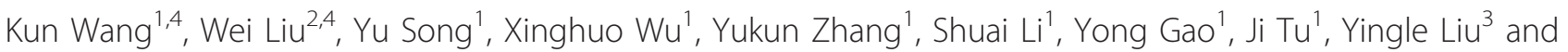 \\ Cao Yang ${ }^{1}$
}

Although evidence shows that intervertebral disc degeneration is generally characterized by angiogenesis, the role of angiopoietin has not been investigated. This study examined the presence of angiopoietin-1 (Ang-1) and angiopoietin-2 (Ang-2) within the native intervertebral disc (IVD) and elucidated their functions in the regulation of nucleus pulposus (NP) cells. Initial investigation of uncultured NP tissue revealed that Ang-1 and Ang-2 were expressed by native NP cells. Ang-2 expression was significantly increased in infiltrated and degenerate samples relative to normal samples. The ratio of Ang2/Ang-1 in tissues from patients increased markedly with increasing age and level of degeneration of the IVD. The ratio of both Ang-2/Ang-1 mRNA and protein increased over time when cells were subjected to constant pressure at $1 \mathrm{Mpa}$ in vitro. Our findings indicate that Ang-2 plays a role in suppressing cell adhesion and viability, and promotes the apoptosis of NP cells and that Ang-2 can inhibit the pathways stimulated by Ang-1 and fibronectin. Ang-2 release during IVD degeneration causes higher ratio of Ang-2 to Ang-1, further inhibits NP cell viability and adhesion, promoting apoptosis by blocking PI3K/Akt signaling. The present study therefore provides new insights into the role of the angiopoietin-Tie system in the pathogenesis of IVD degeneration.

Laboratory Investigation (2017) 97, 971-982; doi:10.1038/labinvest.2017.35; published online 10 April 2017

Low back pain, a major cause of disability, affects 632 million people globally, ${ }^{1}$ and epidemiological studies showing that the incidence of this medical problem increases every year. Although complex multiple factors are involved in triggering lower back pain, the condition is generally believed to be associated with intervertebral disc degeneration (IDD). The progression of degeneration is accompanied by elevated levels of inflammatory cytokines, enhanced degradation of aggrecan and collagen, and changes in the phenotype of disc cells. ${ }^{2}$ Angiogenesis represents an additional feature of disc degeneration; neovascularization enables the infiltration of macrophages into the intervertebral disc (IVD), which triggers inflammation and further accelerates disc degeneration. ${ }^{3}$

The angiopoietin-Tie system is not only crucial for angiogenesis, but also provides an important link between angiogenic and inflammatory pathways. ${ }^{4}$ Two ligands of Tie2, namely angiopoietin-1 (Ang-1) and angiopoietin-2 (Ang-2), have been well characterized; Ang-1, which acts as an anti-inflammatory agent, is required for the stabilization of blood vessels, whereas Ang-2 acts as a functional antagonist of Ang- $1 .{ }^{5}$ Upregulation of Ang-2 expression may represent a critical step in the initiation of inflammatory processes. ${ }^{6}$ Ang-2 activity is sufficient for recruitment of myeloid cells and induction of inflammation even in the absence of proinflammatory stimuli. ${ }^{7}$ The expression of recombinant Ang-2 restores the induction of inflammation in Ang-2deficient mice. ${ }^{8}$ Ang-2 facilitates the expression of tumor necrosis factor and interleukin-1, which are key inflammatory cytokines involved in the upregulation of genes encoding matrix-degrading enzymes in IDD. ${ }^{4,9-11}$ The stimulation of Tie2 results in activation of PI3K/Akt, which has been linked to cell growth, survival, and inhibition of apoptosis. ${ }^{12}$ Previous studies have shown that Ang-1 is crucial for the survival of nucleus pulposus (NP) cells and that the numbers of Tie $2^{+} \mathrm{NP}$ cells decrease during ageing and IVD degeneration. ${ }^{13}$ Thus, we postulated that in normal human

\footnotetext{
'Department of Orthopedics, Union Hospital, Tongji Medical College, Huazhong University of Science and Technology, Wuhan, China; ${ }^{2}$ Department of Orthopedics, First Hospital of Wuhan, Wuhan, China and ${ }^{3}$ State Key Laboratory of Virology, College of Life Sciences, Wuhan University, Wuhan, China Correspondence: Professor C Yang, MD, Department of Orthopedics, Union Hospital, Tongji Medical College, Huazhong University of Science and Technology, Wuhan 430022, China or Professor Y Liu, PhD, State Key Laboratory of Virology, College of Life Sciences, Wuhan University, Wuhan 430022, China.

E-mail: yangcao1971@sina.com or liuyingle1977@sina.com

${ }^{4}$ These two authors contributed equally to this work.
}

Received 10 September 2016; revised 10 February 2017; accepted 15 February 2017 
NP cells that express the Tie2 receptor, pressure-induced IDD increases the Ang-2/Ang-1 ratio, which in turn reduces the cell vitality and induces NP cells apoptosis.

Immunoreactivity against the $\alpha 5 \beta 1$ heterodimer has been observed in non-degenerated as well as degenerated IVDs. ${ }^{14}$ The integrin receptor $\alpha 5 \beta 1$ has been shown to be critical for interactions between IVD cells and fibronectin (FN), revealing functional integrin cell surface receptors that mediate interactions with extracellular matrix proteins in the IVD. ${ }^{15}$ FN is a large extracellular glycoprotein that helps to organize the matrix protein; the main membrane receptor of $\mathrm{FN}$ in NP cells is a $\alpha 5 \beta 1$ integrin subunit. ${ }^{16}$ Stable interactions between the $\alpha 5 \beta 1$ integrin and the Tie 2 tyrosine kinase receptor, which regulate the response to Ang-1, are strengthened by FN in endothelial cells (ECs). ${ }^{17}$ Thus, we hypothesized that Ang-2 induces NP cell apoptosis via the Tie2 tyrosine kinase receptor and $\alpha 5 \beta 1$ integrin signaling.

In this study, we reveal that Ang-2 expression increased with increasing levels of degeneration. Our data demonstrate that the Ang-2/Ang-1 ratio increased in a time-dependent manner when cells were subjected to constant pressure in vitro. Ang-2 inhibits the viability and adhesion of NP cells and induces apoptosis of NP cells, enabling resistance to the effects of Ang-1 and FN. Finally, our data indicated that Tie2 and $\alpha 5 \beta 1$ form a constitutive and specific complex, to which p85 and FAK are recruited. The results of this study show Ang-2 as a pro-degeneration molecule in NP cells.

\section{MATERIALS AND METHODS}

\section{Human NP Tissues: Sample Collection and Staging}

This study was approved by the Institutional Ethics Review Board of Tongji Medical College, Huazhong University of Science and Technology in accordance with the Declaration of Helsinki (2013) of the World Medical Association. NP tissues were collected from patients undergoing spinal surgery. T2weighted magnetic resonance images were obtained at a resolution of 1.5 Tesla. Tissue samples were evaluated using the Thompson Grading System and Pfirrmann Classification System. ${ }^{18}$ Thirty-five patients undergoing surgery for burst fracture $(n=4)$, scoliosis $(n=6)$, lumbar disc herniation $(n=12)$, or spondylolysis $(n=13)$ were enrolled in this study. The age of the patients ranged from 14 to 63 years. There were 6 patients in the grade I group, 8 in the grade II group, 8 in the grade III group, and 13 in the grade IV group. Grades I and II were assigned as non-degenerated disc groups.

Specimens were immediately sectioned for use in various experiments. One section was immediately fixed in $4 \%$ buffered formaldehyde ( $\mathrm{pH}$ 7.4) for eventual histological analysis. A second section was immediately immersed in RNA later (Invitrogen, Carlsbad, CA, USA) and frozen in liquid nitrogen for use in protein and RNA analysis. A third section was immediately immersed in phosphate-buffered saline (PBS) for cell isolation.

\section{Immunohistochemistry}

Tissue samples were embedded in paraffin and then cut into $4-\mu \mathrm{m}$-thick sections. The sections were dewaxed in xylene, then rehydrated in graded alcohol series. Antigen retrieval was performed by microwaving in Tris-EDTA $\mathrm{pH} 9$ for $15 \mathrm{~min}$. After washing with $\mathrm{PBS}$, the endogenous peroxidase activity of the sections was blocked in $3 \% \mathrm{H}_{2} \mathrm{O}_{2}$. Subsequently the samples were incubated with polyclonal anti-Ang-1 (ab8451, Abcam, Cambridge, MA, USA; 1:200 dilution) and anti-Ang2 (sc-7015, Santa Cruz Biotechnology, Santa Cruz, CA, USA; 1:200 dilutions) at $4{ }^{\circ} \mathrm{C}$ overnight. The negative controls included parallel sections treated with PBS solution. After washing, the sections were labeled for $40 \mathrm{~min}$ at $37^{\circ} \mathrm{C}$ with a secondary antibody $(1: 2000)$ conjugated to horseradish peroxidase. After staining with diaminobenzidine (DAB), the sections were counterstained with hematoxylin, and images were captured using a microscope (Olympus IX71, Japan).

\section{Isolation of Nucleus Pulposus Cells}

Normal human NP cells were isolated from the discs in burst fracture patients and young scoliosis patients undergoing deformity correction surgery. The cells were isolated and cultured as previously described. ${ }^{19,20}$ Briefly, NP tissues were minced into small fragments and enzymatically digested in $0.2 \%$ type II collagenase and $0.25 \%$ trypsin for $3 \mathrm{~h}$. After being filtered and washed in PBS, the suspension was centrifuged and the isolated cells were cultured in growth medium (DMEM/F-12 supplied with 20\% fetal bovine serum, $50 \mathrm{U} / \mathrm{ml}$ penicillin, and $50 \mu \mathrm{g} / \mathrm{ml}$ streptomycin) in a $5 \% \mathrm{CO}_{2}$ incubator. The cells were passaged two to three times for use in the following experiments.

\section{Pressure Treatment}

A pressure of $1.0 \mathrm{MPa}$ is widely used to induce IVD degeneration. ${ }^{21}$ The sealed container used in the present study, assembled with a barometer and a thermometer, enabled introduction of compressed gas. The container was placed in an incubator at $37^{\circ} \mathrm{C}$. The cell culture dishes were placed on the clapboard in the container, which contained a small amount of double-distilled water to maintain a humidified atmosphere. A mixture of 5\% $\mathrm{CO}_{2}$ and $95 \%$ compressed air was charged into the container until the pressure reached 1.0 MPa.

\section{Cell Viability Assay}

In all experiments, $2 \times 104$ cells were seeded into 96-well plates. Then, the cells were treated with Ang-2 $(100 \mathrm{ng} / \mathrm{ml})$ or PBS. In another experiment, the stimulation condition consisted of Ang-2 (100 ng/ml) with PBS, Ang-2 (100 ng/ $\mathrm{ml})$ with Ang-1 $(150 \mathrm{ng} / \mathrm{ml})$, or Ang-2 $(100 \mathrm{ng} / \mathrm{ml})$ with the cells pre-plated on FN $(5 \mu \mathrm{g} / \mathrm{ml})$-coated wells for $24 \mathrm{~h}$. After treatment for $30 \mathrm{~min}$, the cells were exposed to $1 \mathrm{MPa}$ pressure for $0,12,24,36$, or $48 \mathrm{~h}$. Cell viability was monitored using the 2-(4,5-dimethyltriazol-2-yl)-2, 5-diphenyl 
tetrazolium bromide (MTT, Sigma) colorimetric assay. Three independent experiments were performed for each experimental condition. Recombinant human Ang-1 and Ang-2 were purchased from R\&D Systems (Minneapolis, MN, USA).

\section{Apoptosis Assay}

Initially, $2 \times 10^{6}$ cells were seeded into 6 -well plates. Then, the cells were treated with Ang-2 $(100 \mathrm{ng} / \mathrm{ml})$ or PBS. In another experiment, the stimulation conditions consisted of Ang-2 $(100 \mathrm{ng} / \mathrm{ml})$ with PBS, Ang-2 (100 ng/ml) with Ang-1 $(150 \mathrm{ng} / \mathrm{ml})$, or Ang-2 $(100 \mathrm{ng} / \mathrm{ml})$ with the cells pre-plated on FN $(5 \mu \mathrm{g} / \mathrm{ml})$-coated wells for $24 \mathrm{~h}$ or Ang-2 $(100 \mathrm{ng} / \mathrm{ml})$ with $740 \mathrm{Y}-\mathrm{P}(500 \mu \mathrm{g} / \mathrm{ml})$. After treatment for $30 \mathrm{~min}$, all samples were exposed to $1 \mathrm{MPa}$ pressure for $0,12,24,36$, or $48 \mathrm{~h}$. Then, the cells were harvested by trypsinization and centrifugation. After two washes in PBS, the resuspended cells were stained with propidium iodide and fluorescein isothiocyanate-conjugated Annexin-V (Beckman Coulter), and incubated in the dark for $15 \mathrm{~min}$ at room temperature. Subsequently, each sample was analyzed using a FACS Calibur Flow Cytometer (BD Biosciences, San Jose, CA, USA). The cells were counted and represented as a percentage of the total cell population using FCS express V2.0 software (De Novo Software, Los Angeles, CA, USA).

\section{Cell Adhesion Assay}

The wells were washed twice with PBS and coated with human plasma FN $(5 \mu \mathrm{g} / \mathrm{ml})$ or FN $(20 \mu \mathrm{g} / \mathrm{ml})$ diluted in PBS, with overnight incubation at $4{ }^{\circ} \mathrm{C}$. After coating, the wells were blocked in PBS plus 3\% BSA. The cells were exposed to $1 \mathrm{MPa}$ pressure for $0,12,24,36$, or $48 \mathrm{~h}$. Then the cells were treated with Ang-2 $(100 \mathrm{ng} / \mathrm{ml})$ and PBS control. In another experiment, groups contained Ang-2 $(100 \mathrm{ng} / \mathrm{ml})$ with PBS; Ang-2 (100 ng/ml) with Ang-1 (150 ng/ml); Ang-2 (100 ng/ $\mathrm{ml})$ with the cells adhesion on FN $(20 \mu \mathrm{g} / \mathrm{ml})$-coated wells. After drug treatments for $30 \mathrm{~min}$, the cells were harvested and plated at 20000 cells per well and allowed to adhere $\left(37^{\circ} \mathrm{C}\right.$; $\left.5 \% \mathrm{CO}_{2} ; 1 \mathrm{~h} ; 5 \mu \mathrm{g} / \mathrm{ml} \mathrm{FN}\right)$. In Ang-2 (100 ng/ml) with the cells adhesion on FN $(20 \mu \mathrm{g} / \mathrm{ml})$-coated wells group, cells finally adhered on FN $(20 \mu \mathrm{g} / \mathrm{ml})$-coated wells. Non-attached cells were removed by vigorous agitation and aspiration. Attached cells were fixed and stained with crystal violet $(0.2 \%$ in $\mathrm{H}_{2} \mathrm{O}$ ). Cell adhesion was quantified by counting the total number of cells per image normalized to that in controls for each treatment.

\section{Immunoprecipitation}

Initially, $2 \times 10^{6}$ cells were seeded into 6 -well plates and allowed to reach $100 \%$ confluence overnight. The cells were stimulated with Ang-2 $(100 \mathrm{ng} / \mathrm{ml})$ and then plated on FN $(5 \mu \mathrm{g} / \mathrm{ml})$, with Ang-1 $(150 \mathrm{ng} / \mathrm{ml})$ and then with Ang-2 $(100 \mathrm{ng} / \mathrm{ml})$; plated on $\mathrm{FN}(5 \mu \mathrm{g} / \mathrm{ml})$ in the presence of varying concentrations of Ang-2; or treated with Ang-1 $(150 \mathrm{ng} / \mathrm{ml})$ in the presence of varying concentrations of Ang-2. After treatments for $30 \mathrm{~min}$, the cells were washed with ice-cold PBS and lysed in lysis buffer containing protease and phosphatase inhibitors. The cell debris was cleared by centrifugation, and the lysates were immunoprecipitated with anti- $\alpha 5 \beta 1$ antibodies $(2 \mu \mathrm{g})$ for $2 \mathrm{~h}$ at $4^{\circ} \mathrm{C}$. In another experiment, lysates were immunoprecipitated with anti-FAK antibodies $(1 \mu \mathrm{g})$. The antibodies were collected on protein A/G beads (Santa Cruz Biotechnology) for $2 \mathrm{~h}$ at $4{ }^{\circ} \mathrm{C}$. The beads were washed with ice-cold lysis buffer and resuspended in SDS sample buffer for blotting analysis specific for Tie2 (ab24859), $\alpha 5 \beta 1$ (ab75472), anti-phosphotyrosine (ab8076) (Abcam), FAK (sc-271195), and p85 (sc-71891) (Santa Cruz Biotechnology).

\section{Western Blotting}

Whole cells from each culture dish were collected and lysed in RIPA buffer containing buffer protease and phosphatase inhibitors. Cells were lysed using membrane protein and cytoplasmic protein extraction kit (Beyotime, Nantong, China). Protein lysates were resolved by SDS-PAGE and transferred onto polyvinylidene fluoride membranes (Amersham Biosciences, USA). The membranes were incubated with primary antibodies $(1: 1000)$ at $4{ }^{\circ} \mathrm{C}$ overnight and secondary antibodies (1:5000) at room temperature for $1 \mathrm{~h}$. The primary antibodies used were as follows: $\alpha 5 \beta 1$ (ab75472) (Abcam), Na-K-ATPase (ab185210), anti-phosphotyrosine (ab8076), phospho-Akt (Ser-473, ab8932), phospho-Akt (T308, ab38449), Akt (ab8805), and tubulin (ab6160) (Abcam); beta actin (sc-47778) and glyceraldehyde-3phosphate dehydrogenase (GAPDH; sc-47724, Santa Cruz Biotechnology). $\beta$-actin, tubulin, Na-K-ATPase, and GAPDH were used as loading controls. Immunoreactive bands were detected using a DAB kit (Zhongshan Goldenbridge, Beijing, China). The protein signals were quantified by scanning densitometry using a FluorChem Q System (Alpha Innotech, CA, USA).

\section{Immunostaining}

Initially, $2 \times 10^{6}$ cells were seeded into 6 -well plates and allowed to attach $100 \%$ confluence overnight. The cells were exposed to $1 \mathrm{MPa}$ pressure for $0,12,24,36$, or $48 \mathrm{~h}$. Subsequently, the cells were mounted on coverslips, washed with PBS, fixed with $4 \%$ paraformaldehyde for $15 \mathrm{~min}$ at $37^{\circ} \mathrm{C}$, permeabilized with $0.5 \%(\mathrm{v} / \mathrm{v})$ Triton $\mathrm{X}-100$ for $20 \mathrm{~min}$, and blocked with $1 \%(\mathrm{w} / \mathrm{v})$ goat serum albumin for $30 \mathrm{~min}$. The samples were then washed, probed at $4{ }^{\circ} \mathrm{C}$ overnight with anti-Ang-1 (1:200) or anti-Ang-2 (1:200), and labeled for $40 \mathrm{~min}$ with a secondary antibody (1:2000). For DNA counterstaining, the samples were incubated in medium containing 4'-6-diamidino-2-phenylindole (DAPI) after washing with PBS. Images were captured using a microscope (Olympus IX71). Tie2 immunostaining was as described above without permeabilization with Triton X-100. Protein expression was quantified by integrated optical density using an Image-Pro Plus image analysis system (Media Cybernetics, Rockville, MD, USA). 


\section{ELISA}

The supernatants were collected. The supernatant levels of Ang-1 and Ang-2 were measured using quantitative ELISA kit (R\&D Systems) according to the manufacturer's instructions. Each sample was tested in duplicate. The results were expressed in $\mathrm{pg} / \mathrm{ml}$.

\section{Real-time PCR}

NP tissues were treated by liquid nitrogen grinding. Total RNA was isolated from NP tissues and cultured cells using TRIzol reagent (Invitrogen). cDNA was synthesized from total RNA using a Transcriptor First Strand cDNA Synthesis Kit (TAKARA Biotechnology, Otsu, Japan). $\beta$-actin was used as an endogenous control. Real-time PCR was performed using SYBR Green Kit Master Mix (Applied Biosystems, Foster City, CA, USA), and the products were analyzed using an ABI 7500 Sequencing Detection System in accordance with the manufacturers' instructions. The primers used for PCR were: Ang-2 (F: 5'-ACTGTGTCCTCTTCCACCAC-3', R: 5'-G GATGTTTAGGGTCTTGCTTT-3'); Ang-1 (F: 5'-CTCCGTA AGGGCTTCCAT-3', R: 5'-CTGCGTCCTCTGTTGTCG-3'); Homo $\beta$-actin (F: 5 '-AGCGAGCATCCCCCAAAGTT-3', R: $5^{\prime}$-GGGCACGAAGGCTCATCATT-3').

\section{Statistical Analysis}

All results are representative of three independent experiments consisting of three replicates per experiment and expressed as the mean \pm s.e.m. Comparisons between groups were conducted by Student's unpaired $t$-test, one-way and two-way ANOVA. Correlations were analyzed using the Spearman correlation coefficient. $P<0.05$ was considered to indicate a statistically significant difference.

\section{RESULTS}

The Ratio of Ang-2/Ang-1 in IDD Tissues Increases with Ageing and Degeneration

In NP tissues of the various extent of degeneration, we detected Ang-1 and Ang-2 expression by immunohistochemistry (Figure 1a). In order to elucidate the role of Ang-1 and Ang-2 in IDD, each NP tissues from surgical specimens with different grades of disc degeneration were analyzed three times by western blotting and RT-PCR (grade I, $n=6$; grade II, $n=8$; grade III, $n=8$; grade IV, $n=13$ ). Signal intensity of individual bands was quantified. Figure $1 b$ shows a set of representative human NP protein extracts loaded in lanes representing surgical samples from patients with varying degrees of degeneration (14 NPs with Pfirrmann grades I-IV, the first normal sample as control). No significant differences in the protein levels of Ang-1 were observed with degree of degeneration (Figure 1c). Grade III IVD was found to be associated with a higher level of Ang-2 than grade II IVD $(P=0.002)$, and the positive bands for Ang-2 were strongest in samples from the patient with grade IV IVD (Figure 1d). The results coincided in transcription level (Figures 1e and $\mathrm{f}$ ). Since Ang-1 and Ang-2 are antagonistic ligands, the Ang-2/ Ang-1 ratio reflects the imbalance between them. The increases in Ang-2/Ang-1 ratio correlated with the extent of disc degeneration (Figures $1 \mathrm{~g}$ and $\mathrm{h}$ ) in both protein and mRNA level. The ratio of Ang-2/Ang-1 in NP tissues was also found to increase with donor age (Supplementary Figure S1). These data strongly suggest that imbalance between Ang-1 and Ang-2 disorganized along with the degeneration.

\section{Compression Mediates an Increase in the Expression of Ang-2 in NP Cells}

Mechanical loading results in alteration of the ECM via exposure of NP cells to mechanical stress. ${ }^{22}$ Numerous studies have reported that persistent mechanical overloading and exposure to compression and torsion induces IDD. ${ }^{23-25}$ In the present study, cells were divided into five groups as follows: control group $(0 \mathrm{~h})$ and four pressure groups, in which cells were exposed to 1.0 MPa pressure for $12,24,36$, and $48 \mathrm{~h}$, and the expression of Ang-2 and Ang-1 was investigated. Results showed that compression promoted protein expression of Ang2 in a time-dependent manner, but did not affect Ang-1 expression markedly (Figures $2 \mathrm{a}$ and $\mathrm{b}$ ). The Ang-2/Ang-1 ratio increased with the duration of exposure to mechanical stress at the mRNA level (Figure 2c). As Ang-1 and Ang-2 are secreted proteins, their concentration in the supernatant of NP cell cultures was detected by enzyme-linked immunosorbent assay (ELISA). These results were consistent with the observed mRNA and protein expression levels of Ang-2 and Ang-1 (Figure 2d). In addition, an increase in the protein levels of Ang-2 was detected by immunofluorescence; however, no obvious change in Ang-1 protein levels occurred in response to compression in NP cells (Figure 2e).

\section{Effect of Ang-2 on NP Cells}

FN is thought to initiate matrix assembly by forming large aggregates in the matrix, resulting in the generation of a fibrillar meshwork ${ }^{26}$ that provides binding sites for several cell membrane and matrix proteins involved in transmitting important information to NP cells. ${ }^{15,27}$ We therefore examined the ability of Ang-2 to interfere with the adhesion of NP cells to FN. The cells were treated with $1.0 \mathrm{MPa}$ pressure for $0,12,24,36$, or $48 \mathrm{~h}$. Ang-2-mediated stimulation of NP cells inhibited binding to FN (Figure 3a). The differences between the two groups were significant when compression was applied for 24,36 , and $48 \mathrm{~h}$. On addition of Ang-1 to the culture medium or adhesion to higher concentrations of FN-coated plates, the Ang-2-induced loss of adhesion of NP cells to $\mathrm{FN}$ was partially restored (Figure $3 \mathrm{~b}$ ). In addition, we investigated the possible role of Ang-2 in the degeneration of NP tissue by assessing cell viability using the MTT assay in NP cells subjected to mechanical stress. In the presence of Ang-2, cell viability declined more sharply on exposure to stress compared with the control group. The differences between the two groups were statistically significant after pressure was applied for 24, 36, and $48 \mathrm{~h}$ (Figure 3c). However, this decline was partially rescued by Ang-1 and FN (Figure 3d). Following treatment 
a

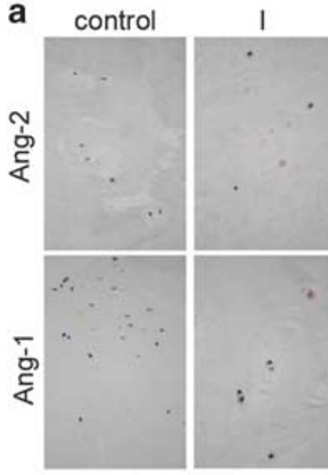

c

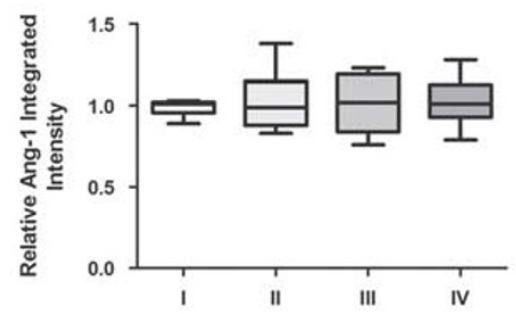

e

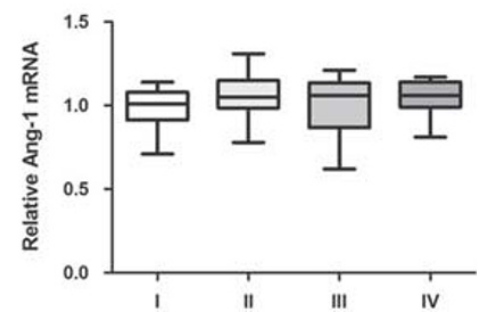

II
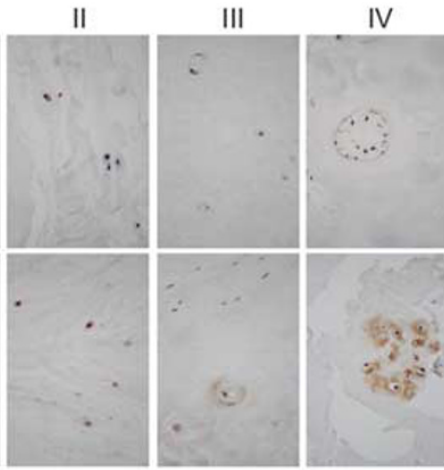

b

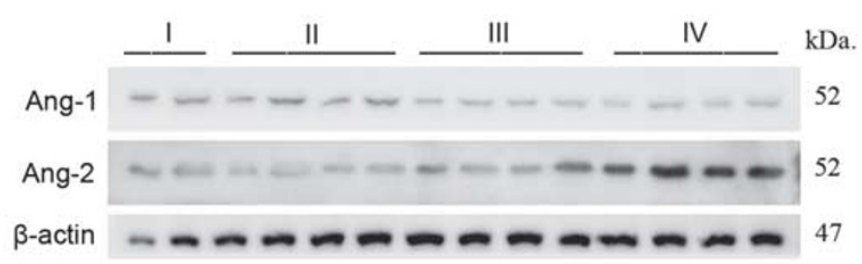

d

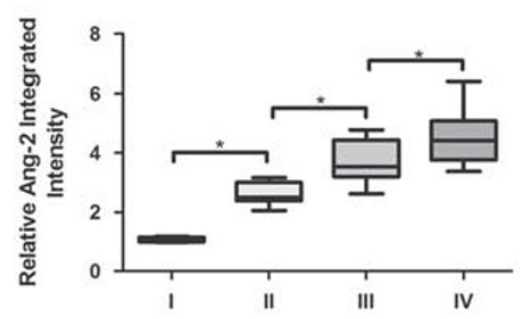

f

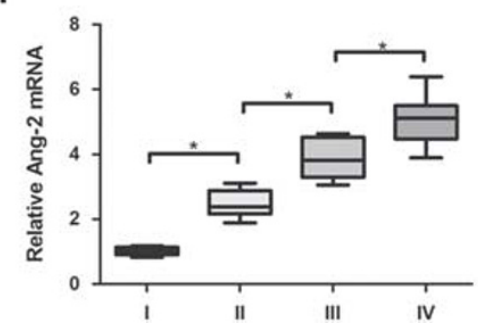

g

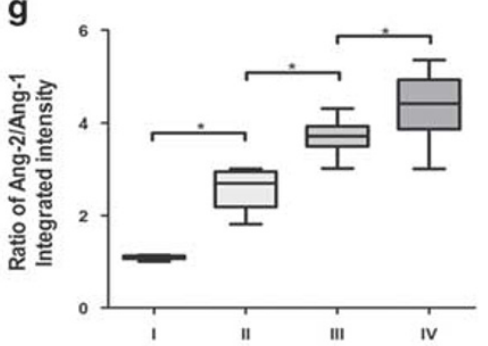

h

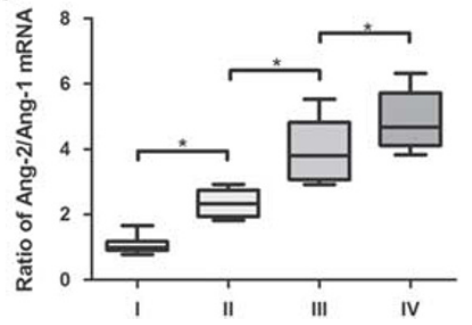

Figure 1 Ratio of Ang-2/Ang-1 is elevated in NP tissue. (a) Immunohistochemistry of collected NP samples in different extents of degeneration. (b) Western blot of collected NP samples using the Ang-1 and Ang-2 antibody. (c, d) Quantitative western blot analysis of Ang-1 and Ang-2 expression in NP samples. (e, f) Real-time PCR analysis of Ang-1 and Ang-2 expression in NP samples. (g, h) Correlation of Ang-2/Ang-1 ratio in NP tissues with intervertebral disc degeneration. ${ }^{*} P<0.05$. Ang-1, angiopoietin-1; Ang-2, angiopoietin-2; NP, nucleus pulposus.

with Ang-2, an increase in compression-induced apoptosis of NP cells was observed using flow cytometry (Figures $3 \mathrm{e}$ and f). As shown in Figures 3g and h, Ang-1 and FN exerted protective effects against apoptosis in NP cells under mechanical stress. PI3K-activating peptide (740Y-P) binds to the $\mathrm{SH} 2$ domain of the p85 regulatory subunit of PI3K to stimulate enzyme activity. ${ }^{28} 740 \mathrm{Y}-\mathrm{P}$ was found to block the Ang-2-induced apoptosis of NP cells, indicating that PI3K plays a role in Ang-2-induced outside-in signaling (Figures $3 \mathrm{~g}$ and h). Our findings indicate that Ang-2 plays a role in suppressing cell adhesion and viability, and promotes the apoptosis of NP cells.

\section{Ang-2 Antagonizes the FN- and Ang-1-Induced Formation of the Tie2/a5 $\beta 1$ Complex in NP Cells}

In order to characterize the molecular signaling mechanisms underlying the apoptosis of NP cells, we investigated expression of Tie2 receptors in cultured normal NP cells initially.
Immunofluorescence studies detected Tie2 receptor in the cytomembrane (Supplementary Figure S2). Then the regulation of Tie $2 / \alpha 5 \beta 1$ interactions in these cells was investigated. When NP cells were stimulated by Ang-1 or plated on FN, the amount of Tie 2 co-immunoprecipitated with $\alpha 5 \beta 1$ integrin was remarkably higher than that when cells were grown in culture medium. This effect was partially abrogated by Ang-2 (Figures $4 \mathrm{a}$ and $\mathrm{b}$ ). The ability of Ang-2 to antagonize the interaction enhanced by either FN or Ang-1 was dosedependent (Figures $4 \mathrm{c}$ and $\mathrm{d}$ ). The observed inhibitory phenotype of Ang-2 led us to examine the effect of Ang-2 on the induction of $\alpha 5 \beta 1$; our findings revealed that the expression of $\alpha 5 \beta 1$ is not affected by the presence or absence of Ang-2 (Figure 4e). However, translocation of $\alpha 5 \beta 1$ was detected under Ang-2 stimulation, and membrane $\alpha 5 \beta 1$ was found to accumulate in the cytoplasm (Figure 4f). To further confirm this finding, $\alpha 5 \beta 1$ translocation was assessed by western blot analysis using membrane and cytosolic extracts (Figure 4g). 
a

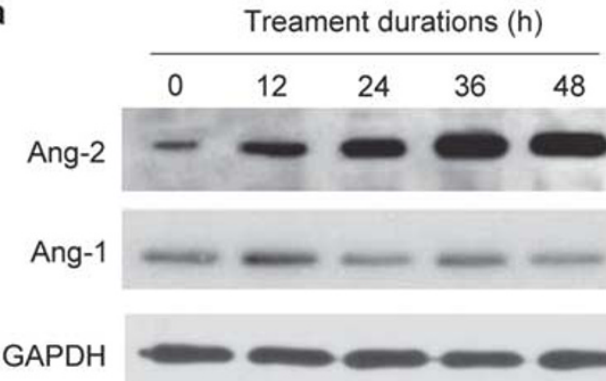

$\mathrm{kDa}$.

70

57

37

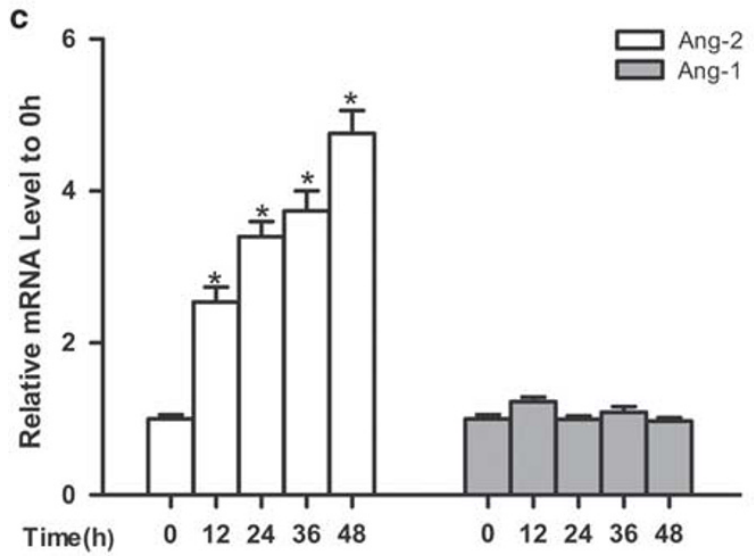

e

Ang-1

ธ

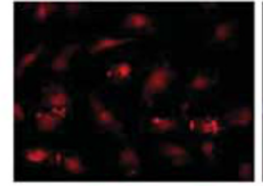

ำ

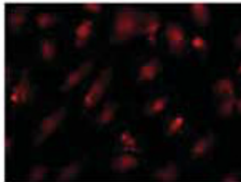

รัป

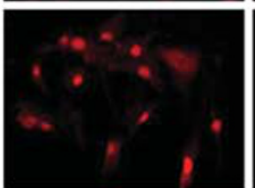

్ㅏㅇ
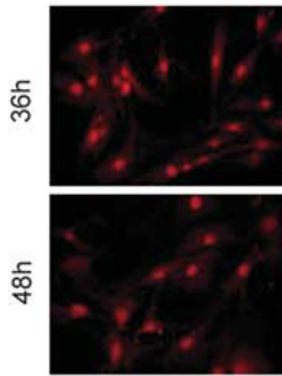

Merge
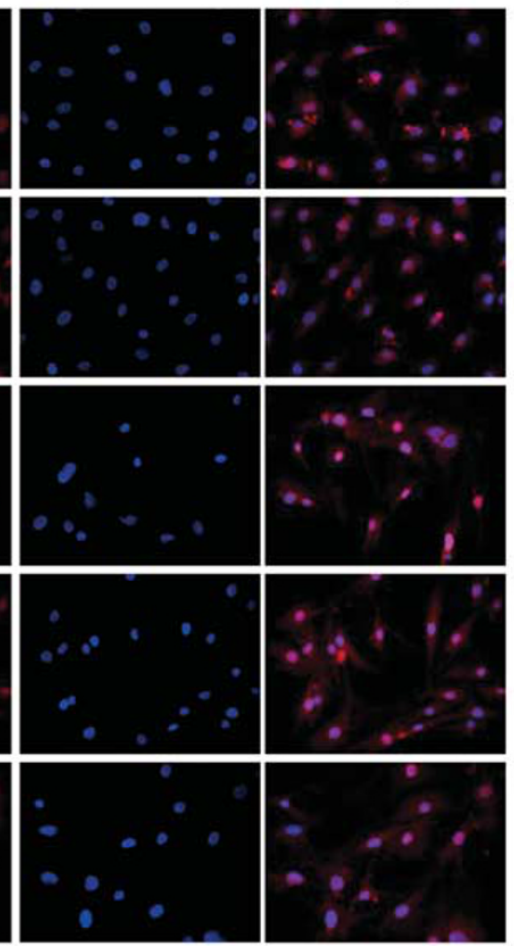

b

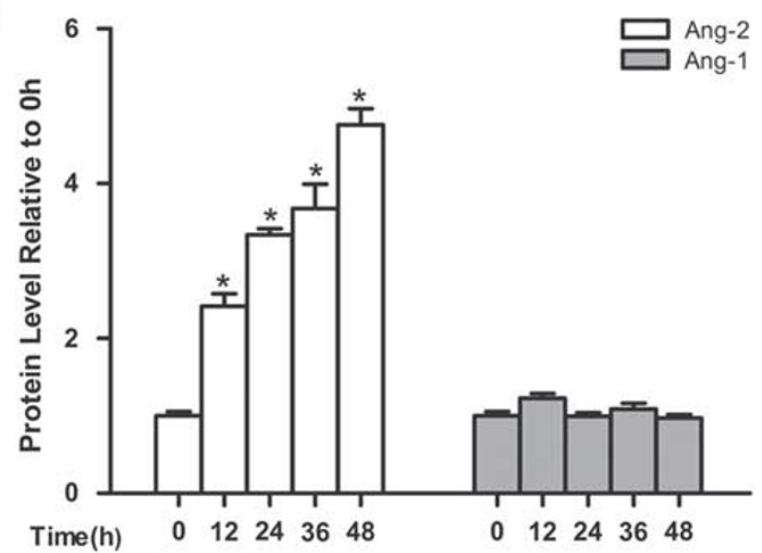

d

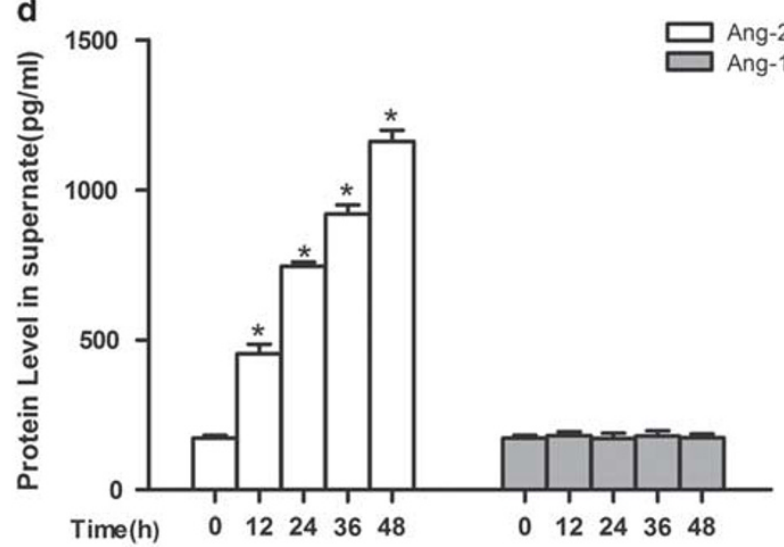

Ang-2

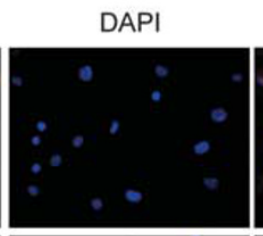

Merge

등

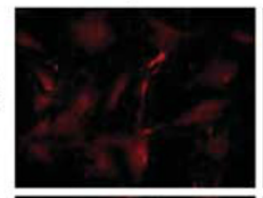

ิㅡㄴ
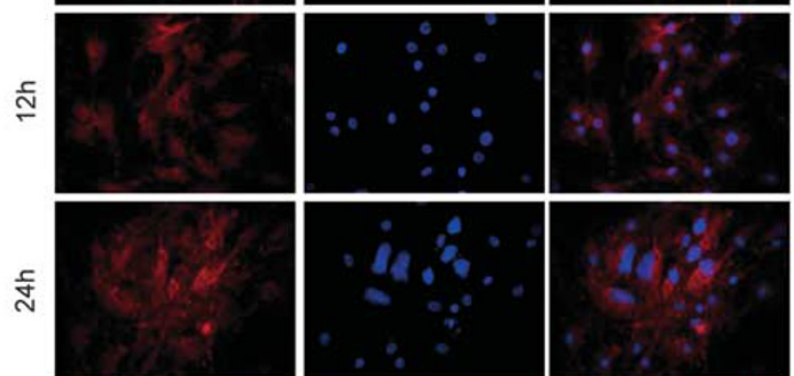

당
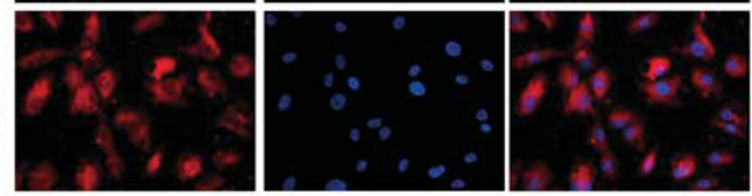

돔

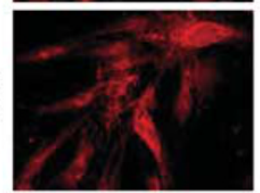


a

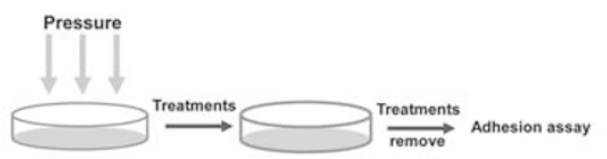

C
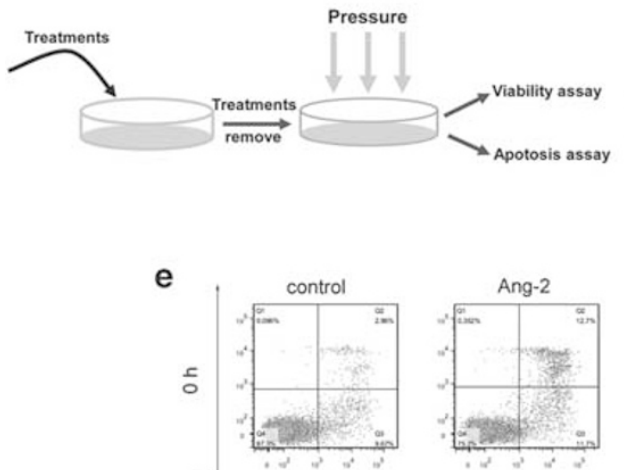

$\mathrm{PI}$

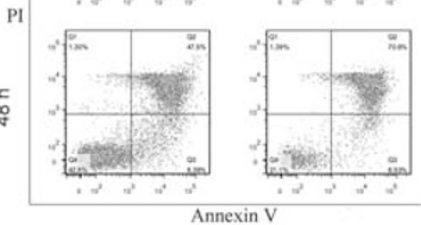

f

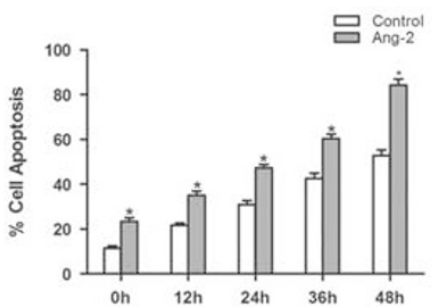

g Ang-2+Control Ang-2+Ang-1
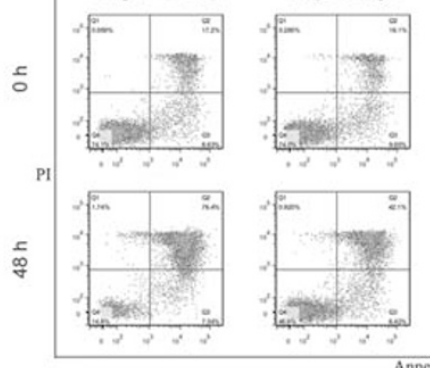

h

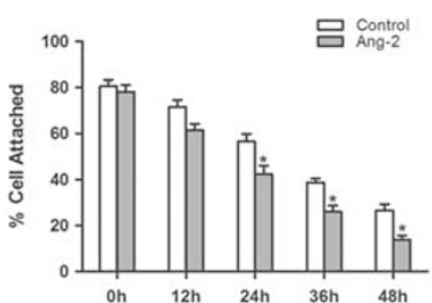

b

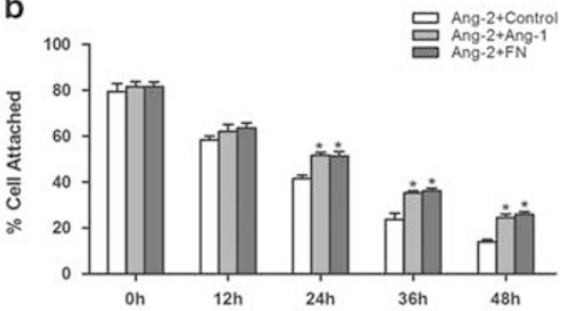

d

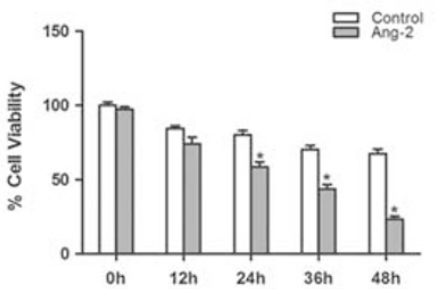

古g $2+2+$ Control
Ang-2+Ang-1
Ang-2+FN

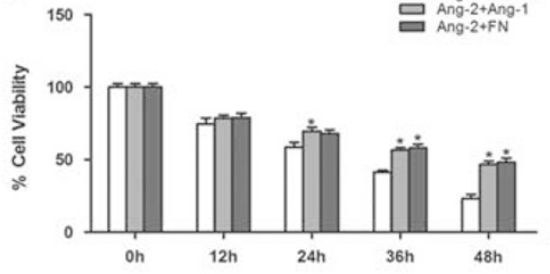

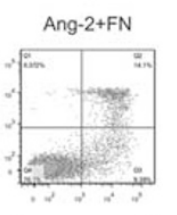

Ang- $2+740 Y-P$
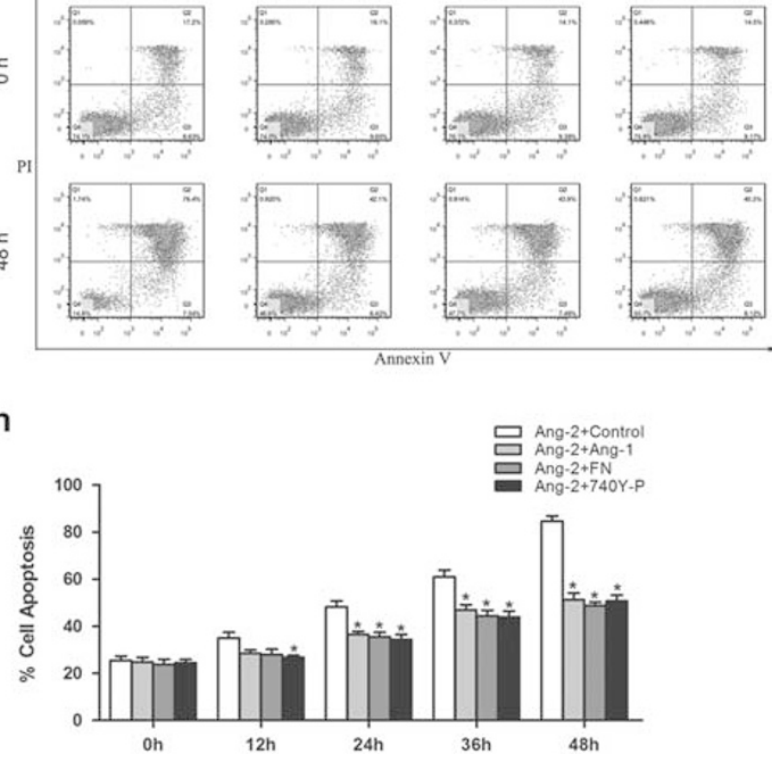

Figure 3 Function of Ang-2 in human NP cells. (a) A schematic of the treatment protocols for cell attachment assays. The adhesion of cells to FN $(5 \mu \mathrm{g} / \mathrm{ml})$ stimulated by Ang-2 $(100 \mathrm{ng} / \mathrm{ml})$ and control. (b) The adhesion of cells to FN $(5 \mu \mathrm{g} / \mathrm{ml})$ stimulated by Ang-2 (100 ng/ml) with Ang-1 $(150 \mathrm{ng} / \mathrm{ml})$; Ang-2 $(100 \mathrm{ng} / \mathrm{ml})$ with control and to FN $(20 \mu \mathrm{g} / \mathrm{ml})$ stimulated by Ang-2 $(100 \mathrm{ng} / \mathrm{ml})$. (c) A schematic of the treatment protocols for cell viability and apoptosis assays. The cells were stimulated by Ang-2 $(100 \mathrm{ng} / \mathrm{ml})$ and control to measure viability by MTT assay. (d) The cells were stimulated by Ang-2 $(100 \mathrm{ng} / \mathrm{ml})$ with Ang-1 $(150 \mathrm{ng} / \mathrm{ml})$; Ang-2 $(100 \mathrm{ng} / \mathrm{ml})$ with plated on FN $(5 \mu \mathrm{g} / \mathrm{ml})$; Ang-2 $(100 \mathrm{ng} / \mathrm{ml})$ with control to measure viability by MTT assay. (e) Representative flow cytometry data of 0 and $48 \mathrm{~h}$ cell apoptosis in two groups. (f) The cells were stimulated by Ang-2 $(100 \mathrm{ng} / \mathrm{ml})$ and control to analyze apoptosis by flow cytometry. (g) Representative flow cytometry data of 0 and $48 \mathrm{~h}$ cell apoptosis in different groups. (h) The cells were stimulated by Ang-2 (100 ng/ml) with Ang-1 $(150 \mathrm{ng} / \mathrm{ml}) ;$ Ang-2 $(100 \mathrm{ng} / \mathrm{ml})$ with plated on FN $(5 \mu \mathrm{g} / \mathrm{ml}) ;$ Ang-2 $(100 \mathrm{ng} / \mathrm{ml})$ with control to analyze apoptosis by flow cytometry. $n=3,{ }^{*} P<0.05$ vs control. Ang-1, angiopoietin-1; Ang-2, angiopoietin-2; FN, fibronectin; NP, nucleus pulposus.

Figure 2 Effects of compression on mRNA and protein expression of Ang-1 and Ang-2. (a) The protein content of Ang-1 and Ang-2 detected in human NP cells subjected to compression at $1.0 \mathrm{MPa}$ for various durations. (b) Densitometric analysis shows the relative amount of Ang-1 and Ang-2 detected in human NP cells. (c) The mRNA levels of Ang-1 and Ang-2 detected by RT-PCR in human NP cells subjected to compression at $1.0 \mathrm{MPa}$ for various durations. (d) The levels of Ang-1 and Ang-2 in supernatant detected by ELISA in human NP cells subjected to compression at $1.0 \mathrm{MPa}$ for various durations. (e) The fluorescent staining of Ang- 1 and Ang-2 in human NP cells subjected to compression at $1.0 \mathrm{MPa}$ for various durations. $n=3,{ }^{*} P<0.05$ vs $0 \mathrm{~h}$ group. Ang-1, angiopoietin-1; Ang-2, angiopoietin-2; ELISA, enzyme-linked immunosorbent assay; mRNA, messenger RNA; NP, nucleus pulposus; RT-PCR, real-time PCR. 
a
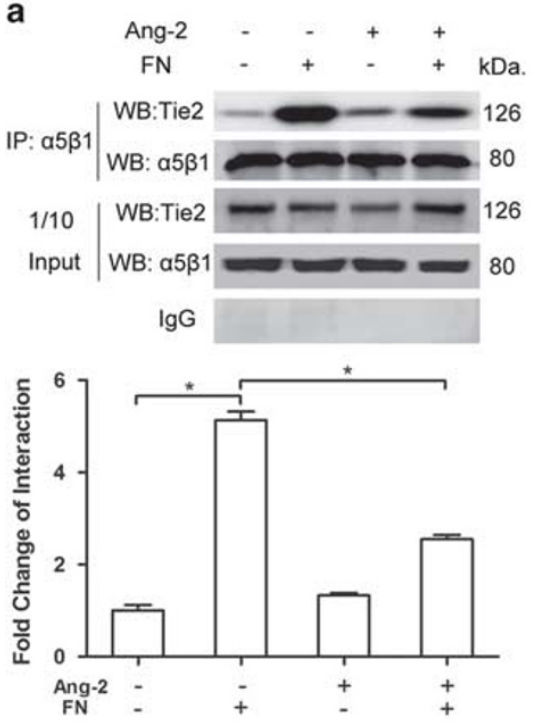

d

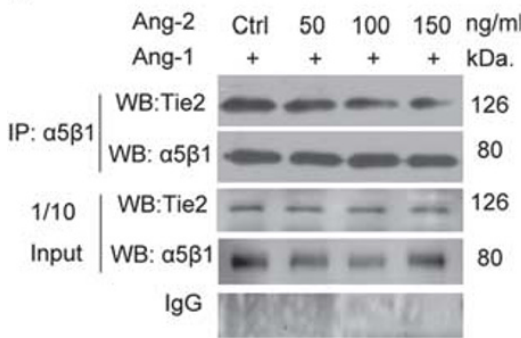

f

Intergrin: $\alpha 5 \beta 1$

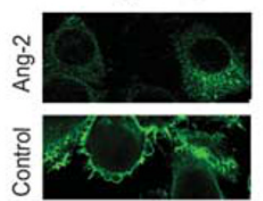

g b
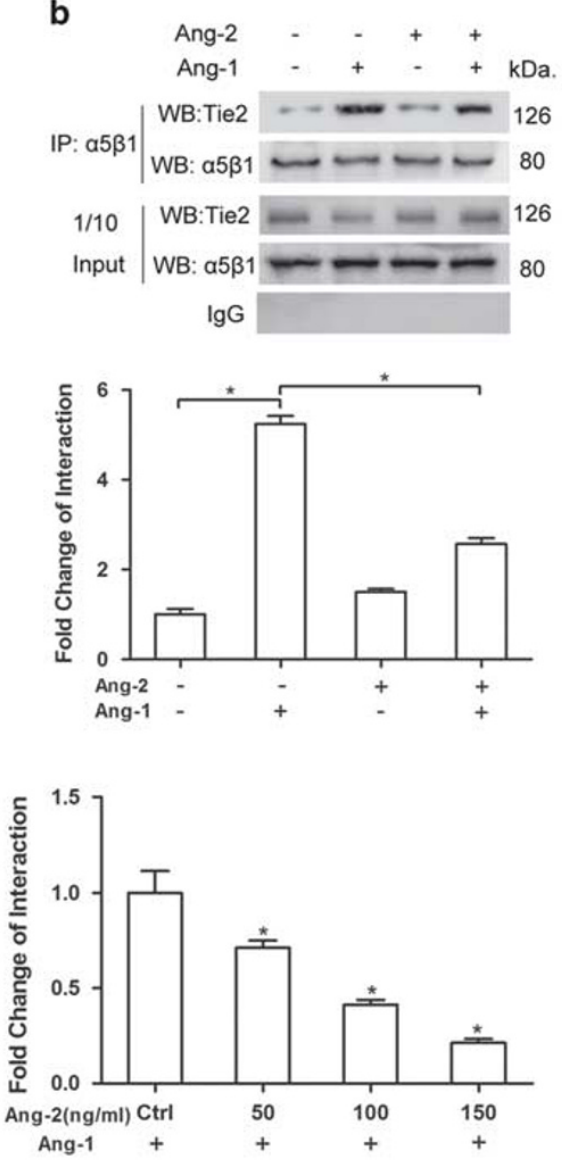

C
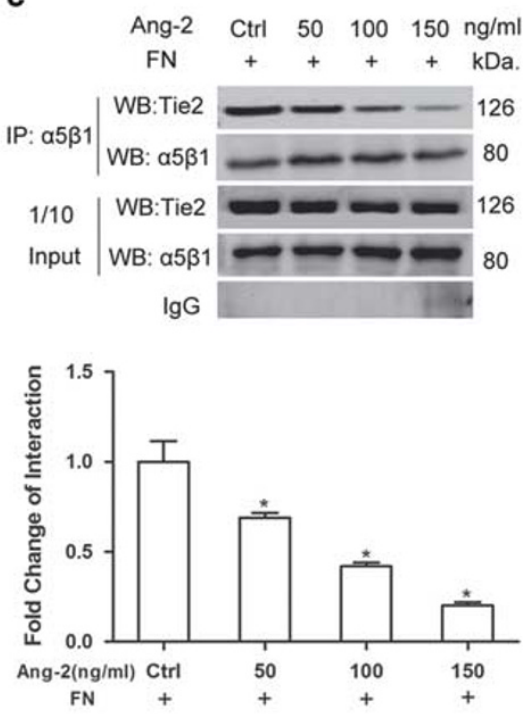

e
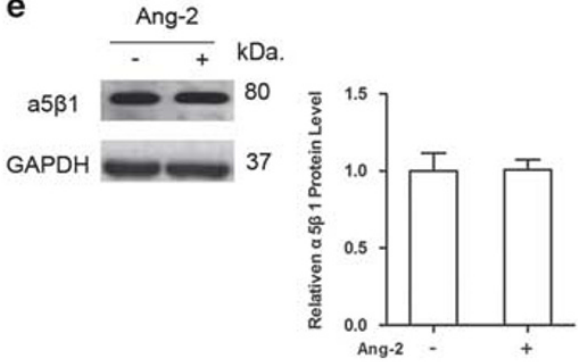
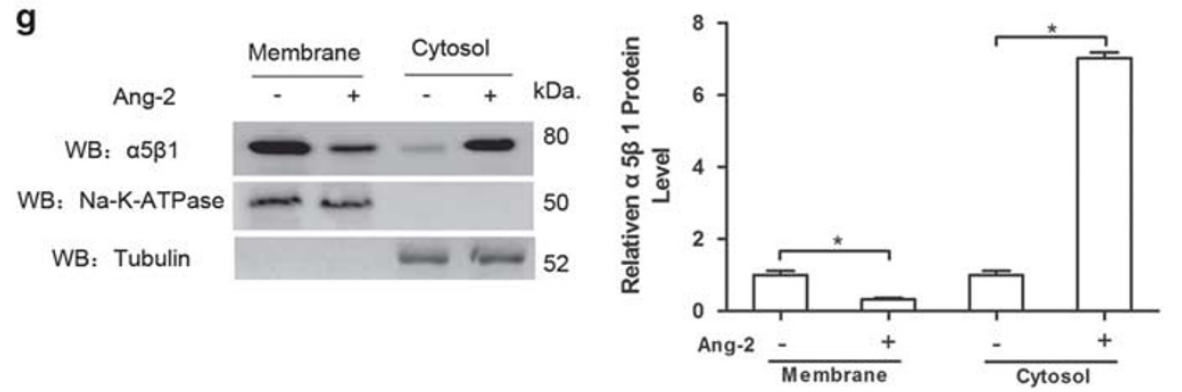

Figure 4 Ang-2 suppresses Tie2/a5 $\beta 1$ complex formation. (a) Immunoprecipitation assays using anti-a5 $\beta 1$ antibody were performed on lysates of NP cells that were cultured on FN-coated or uncoated plates and treated with or without Ang-2 $(100 \mathrm{ng} / \mathrm{ml})$. Densitometric analysis shows the relative amounts of Tie 2 in $a 5 \beta 1$ immunoprecipitates. $n=3,{ }^{*} P<0.05$. (b) Immunoprecipitation assays using anti- $a 5 \beta 1$ antibody were performed on lysates of NP cells that were cultured on Ang-1-contained or uncontained plates and treated with or without Ang-2 (100 ng/ml). Densitometric analysis shows the relative amounts of Tie2 in $a 5 \beta 1$ immunoprecipitates. $n=3$, ${ }^{*} P<0.05$. (c) NP cells were plated on FN $(5 \mu \mathrm{g} / \mathrm{ml})$ in the presence of varying concentrations of Ang- 2 and then lysed for immunoprecipitation by anti- $\alpha 5 \beta 1$. Densitometric analysis shows the relative amounts of Tie 2 in $a 5 \beta 1$ immunoprecipitates. $n=3, * P<0.05$ vs Ctrl. (d) NP cells were cultured with Ang-1 $(150 \mathrm{ng} / \mathrm{ml})$ in the presence of varying concentrations of Ang- 2 and then lysed for immunoprecipitation by anti- $a 5 \beta 1$. Densitometric analysis shows the relative amounts of Tie2 in $a 5 \beta 1$ immunoprecipitates. $n=3,{ }^{*} P<0.05$ vs Ctrl. (e) Representative western blotting images and quantification data displaying the levels of integrin $\alpha 5 \beta 1$ after Ang- 2 stimulation. $n=3$, ${ }^{*} P<0.05$. (f) $a 5 \beta 1$ translocation following Ang-2 stimulation was investigated by immunofluorescence. (g) The expression of $a 5 \beta 1$ was assessed by western blotting and quantified using membranes and cytosolic extracts. $n=3,{ }^{*} P<0.05$. Ang-1, angiopoietin-1; Ang-2, angiopoietin-2; FN, fibronectin; NP, nucleus pulposus.

\section{Ang-2 Suppresses the Recruitment of FAK and p85 in NP Cells}

Previous reports have suggested that PI3K plays a role in Ang2 -induced apoptosis (Figure 3f); recruitment of the $\alpha 5 \beta 1$ adaptor protein FAK results in $\mathrm{p} 85$ phosphorylation, thereby activating Tie2 to induce PI3K signaling. ${ }^{29}$ To further examine the signaling activity resulting from the interaction between Tie 2 and $\alpha 5 \beta 1$, we assessed the recruitment of FAK and the $\mathrm{p} 85$ subunit of PI3K to the complex. Compared to FN or Ang-1 stimulation alone, Ang-2 administration reduced 
a
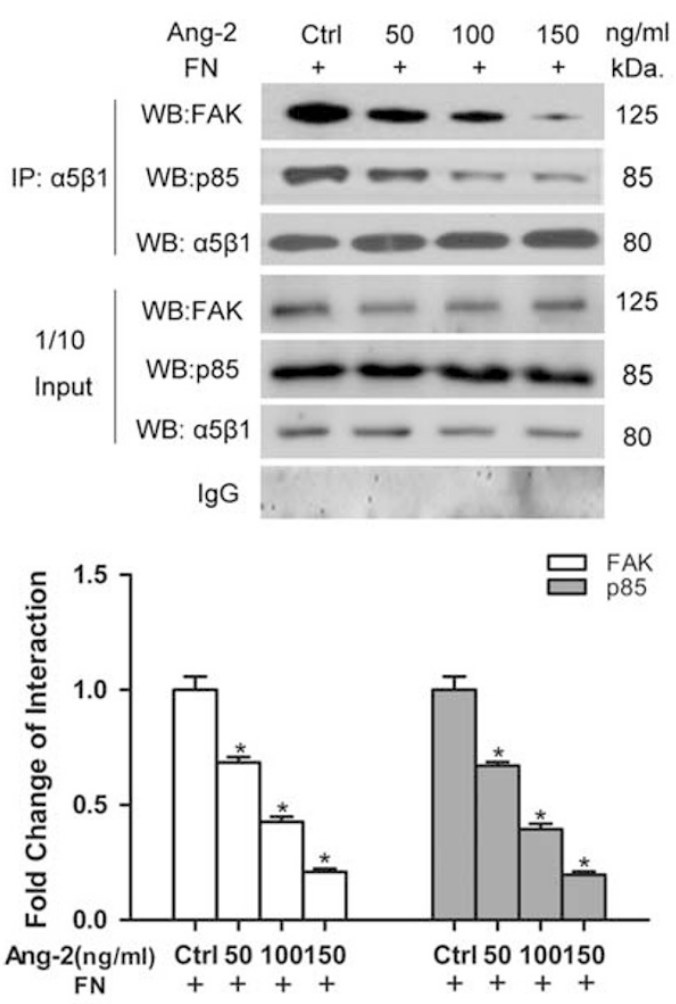

c

$$
\begin{array}{cccccccc}
\text { Ang-2 } & - & - & - & + & + & + & \\
\text { Ang-1 } & - & - & + & - & - & + & \\
\text { FN } & - & + & - & - & + & - & k D a
\end{array}
$$
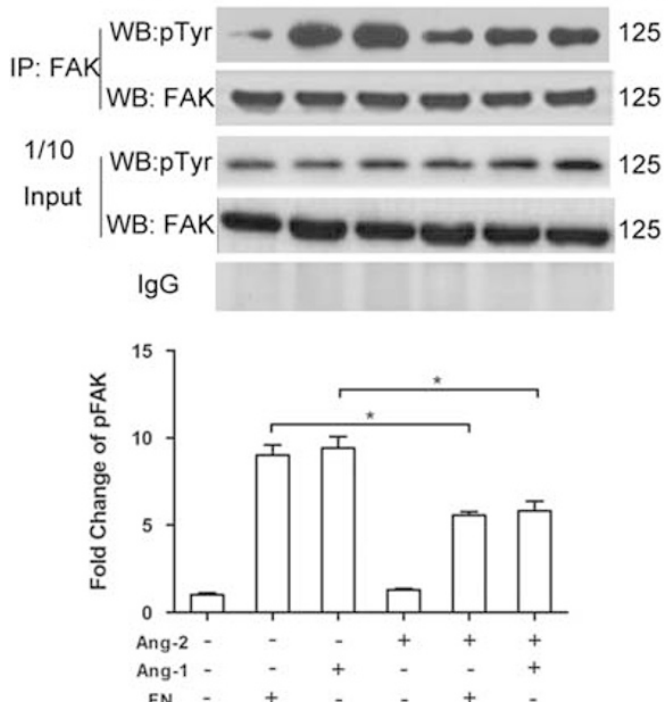

b
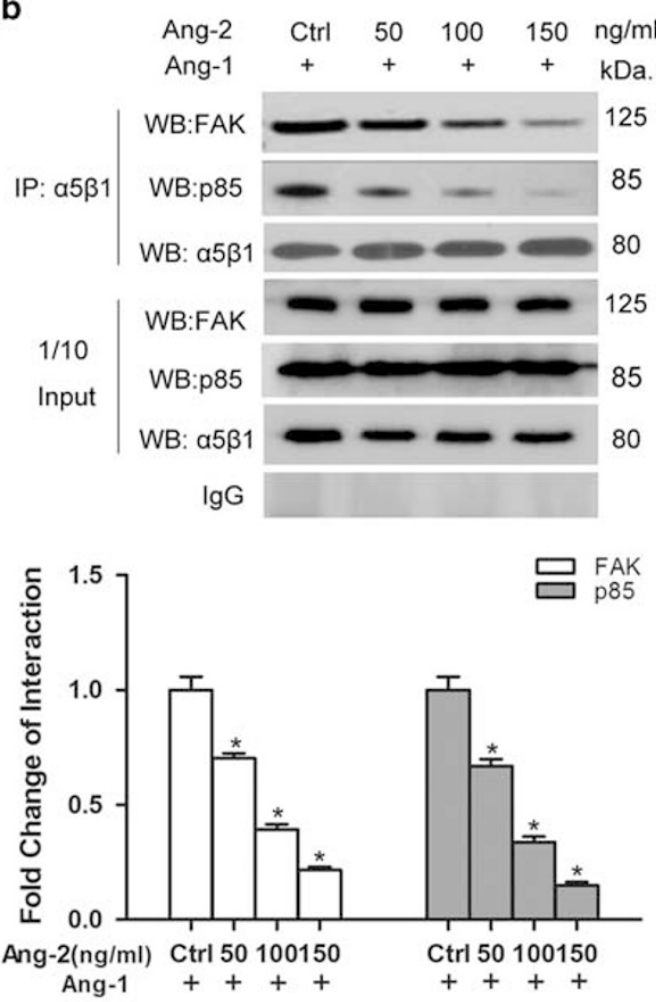

d
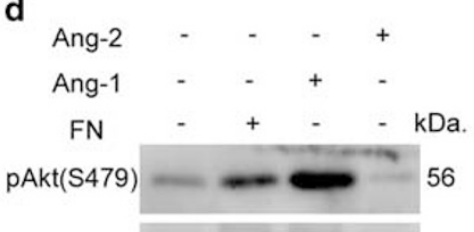

pAkt(T308)

Akt

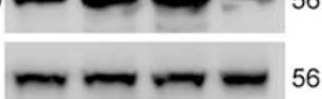

e

$\beta$-actin
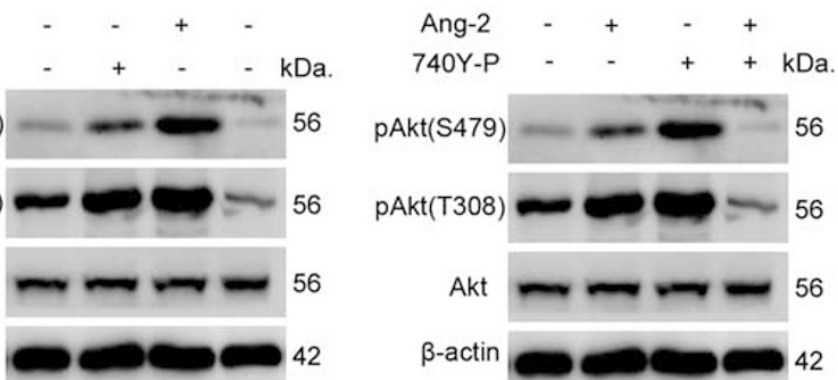

$\operatorname{pAkt(T308)}=56$

Akt

$\beta$-actin
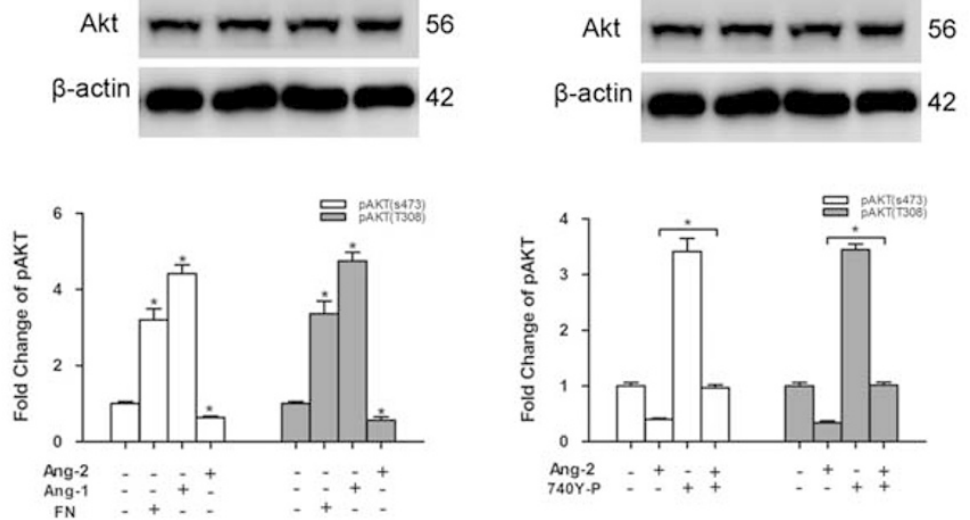

Figure 5 Ang-2 suppresses the recruitment of FAK and p85. (a, b) NP cells were cultured on FN (5 $\mu \mathrm{g} / \mathrm{ml})$ or with Ang-1 (150 ng/ml) in the presence of indicated concentrations of Ang-2 and lysed for immunoprecipitation, followed by immunoblotting and quantification for FAK and p85. $n=3, * P<0.05$ vs control. (c) pFAK was immunoblotted using anti-phosphotyrosine after immunoprecipitation with anti-FAK. The fold increase in FAK tyrosine phosphorylation was determined by densitometric analysis. (d) pAKT was immunoblotted and quantified to display the relative phosphotyrosine level of AKT in NP cells exposed to Ang-2, Ang-1, and FN, respectively. (e) pAKT was immunoblotted and quantified to display the relative phosphotyrosine level of AKT in NP cells exposed to Ang-2 and 740Y-P, respectively. $n=3,{ }^{*} P<0.05$. Ang-1, angiopoietin-1; Ang-2, angiopoietin-2; FN, fibronectin; NP, nucleus pulposus. 


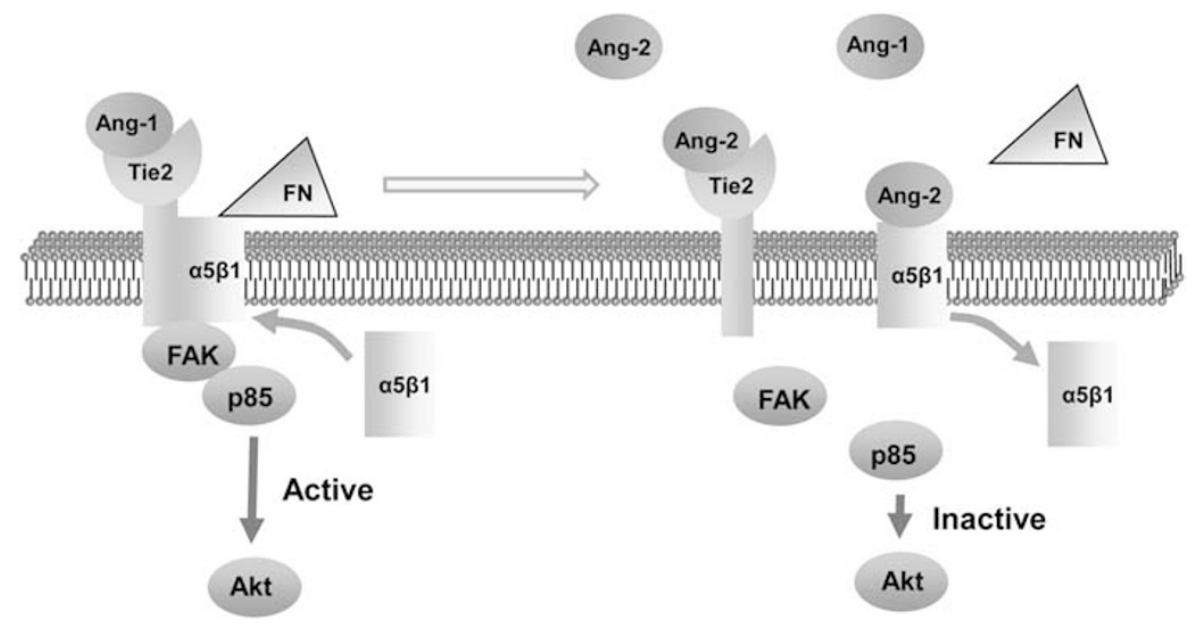

Figure 6 Schematic representation of Ang-2-regulated Tie2 tyrosine kinase receptor and $a 5 \beta 1$ integrin signaling in NP cells. Ang-1 acts as a ligand to activate Tie2 receptor. Integrin $a 5 \beta 1$ is assembled to Tie2 after FN stimulation and recruits FAK and p85, which further activate Akt signaling. When Ang-2 increases, Ang-2 interferes with Ang-1-induced Tie2 activation and Ang-2-a5 $\beta 1$ interaction may induce $a 5 \beta 1$ to translocation, leading to disassemble the complex of Tie2 and $a 5 \beta 1$. The subsequent decreased recruitment of FAK and p85 ultimately brings down Akt activity. Ang-1, angiopoietin-1; Ang-2, angiopoietin-2; FN, fibronectin; NP, nucleus pulposus.

the recruitment of FAK and p85 to $\alpha 5 \beta 1$ in a dose-dependent manner after $\alpha 5 \beta 1$ immunoprecipitation (Figures $5 \mathrm{a}$ and $\mathrm{b}$ ). Stimulation of NP cells by Ang-2 not only reduced the association of Tie2 with $\alpha 5 \beta 1$, but also decreased the recruitment of FAK and p85 to the complex. The FN- and Ang-1-stimulated phosphorylation of FAK was reduced by Ang-2 (Figure 5c). Next, we examined the phosphorylation of AKT; pAKT levels increased in the presence of FN or Ang-1, whereas treatment with Ang-2 reduced pAKT levels (Figure 5d). 740Y-P reduced the inhibition of the Ang-2stimulated PI3K/AKT axis (Figure 5e). Taken together, these data indicate that Ang-2 suppresses the phosphorylation and function of the integrin adaptor protein FAK, as well as that of p85 to exert inhibitory effect via PI3K/AKT signaling in NP cells.

\section{DISCUSSION}

Ang/Tie signaling, which was initially found to occur in the endothelium-specific tyrosine kinase system, plays an important role in multiple cells and tissue systems. Ang-1 and Ang-2 are expressed at sites of endochondral bone formation in the growing skeleton. ${ }^{30}$ Mesenchymal stem cells, which express Ang-1 and high levels of Ang-2, exhibit a strong ability to elicit remodeling of preexisting vasculature at the injured site and support new vessel formation. ${ }^{31}$ Moreover, accumulating evidence shows that expression of Ang-2 by tumor cells is linked with invasive and metastatic phenotypes of gastric, colon, brain, prostate, and breast cancers. ${ }^{32}$ To our knowledge, the present study is the first to report that Ang-2 is expressed by NP cells, and that the Ang-2/Ang-1 ratio in these cells increases in IDD. We showed that the acceleration of pressure-induced degeneration in NP cells, which is exasperated by induction of Ang-2, decreased NP cell viability, adhesion, and promoted apoptosis.

The factors contributing to the strong correlation between the ratio of Ang-2/Ang-1 and degree of IDD were explored. The molecular phenotype of NP cells derived from normal discs was examined, and the expression of the Tie2 receptor in the cytomembrane was confirmed. Integrins participate in mechanotransduction in human NP cells by acting as mechanoreceptors that detect mechanical stimulation by dynamic loading. ${ }^{33}$ Although Tie2 is a Ang-2 receptor, it is capable of forming a complex with integrins. Numerous studies have suggested that Ang-2 exhibits context-dependent functions, eg, It acts as a vessel-destabilizing molecule in Tie2expressing ECs and as a directly pro-angiogenic molecule in Tie2-negative angiogenic ECs via integrin signaling. ${ }^{34}$ Ang-2 interacts directly with $\alpha 5 \beta 1$ integrins and activates downstream effectors to promote tumor migration. ${ }^{35}$ When acting alone, Ang-2 does not induce apoptosis; however, at high concentrations of glucose, such as in diabetic retinopathy, it induces apoptosis in pericytes via $\alpha 3 \beta 1$ integrin signaling. ${ }^{36}$ As seen in the ELISA experiments (Figure 2d), the physiological levels of Ang-2 may be at the $1 \mathrm{ng}$ range, which contribute to NP cells survival. In the experiments, concentrations of Ang-2 were well above physiological $(100 \mathrm{ng} / \mathrm{ml})$ and these higher levels cause apoptosis as well as reduction of cell viability and adhesion. Our findings are consistent with those of previous studies. Following the activation of Tie2 signaling by Ang- $1, \alpha 5 \beta 1$ binds to the complex; this interaction is enhanced by FN. Ang-2 weakens this Ang-1and $\mathrm{FN}$-induced interaction. Interestingly, the interaction between Tie 2 and $\alpha 5 \beta 1$ is mildly enhanced in the presence of Ang-2 alone. The basis for the discrepancy between these conditions is unclear but potentially could result from 
differences in the method of Ang-2 delivery and require further investigation. Collectively, the data establish a contextual model according to which molecular interactions are differentially regulated by Ang- 2 in response to specific conditions. Ang-2 and Ang-1 exhibited similarly high binding affinity for Tie2. ${ }^{37}$ Ang-1 induces rapid autophosphorylation of Tie2 receptors to activate the downstream signaling pathway. Ang-2, which is $60 \%$ identical to Ang-1, binds to Tie2 without inducing phosphorylation. ${ }^{38}$ When the Ang-2/ Ang-1 ratio increases, Ang-2 acts as a competitive blocking antagonist via Tie2 receptor tyrosine kinase. The enhancement of the Tie $2 / \alpha 5 \beta 1$ signal by the combination of Ang- 1 and fibronectin was inhibited by the Ang-2-induced Tie2 phosphorylation decrease.

It has been reported that the binding of $\mathrm{FN}$ to integrin $\alpha 5 \beta 1$ results in elevated expression of the Bcl- 2 protein, which is known to counteract apoptosis. Conversely, abrogation of FN-integrin $\alpha 5 \beta 1$ interactions has been shown to induce apoptosis. ${ }^{39}$ In this study, FN was found to exert positive effects on NP cells. Furthermore, we demonstrated that FN partly offsets, but not completely reverses, the negative effects of Ang-2 on NP cells; unexpectedly, we found that $\alpha 5 \beta 1$ translocates from the membrane to the cytoplasm and that Ang-2 does not affect the total expression of $\alpha 5 \beta 1$. The review by Huang et al ${ }^{5}$ shows that Ang-2 binds to $\alpha 5 \beta 1$ directly. The case, binding of Ang-2 to $\alpha 5 \beta 1$, may cause the complex to internalize that conform to our findings (Figure 6). Some studies have indicated that the levels of FN are elevated in degenerate discs, and this protein is frequently observed as fragments. Elevated levels of FN reflect the response of disc cells to the altered environment. FN fragments result from normal or enhanced proteolytic activity, which may induce further degradation of the matrix. ${ }^{27}$ Other findings support a pathological role for FN fragments in disc degeneration in the rabbit. ${ }^{40,41}$ When $\mathrm{FN}$ is cleaved into fragments, $\mathrm{FN}$-integrin $\alpha 5 \beta 1$ interactions may be diluted leading to enhanced apoptosis.

Recent studies have shown that rat NP cells adapt for survival by the regulation of expression of critical genes, eg, the activation of the PI3K/Akt and MAPK survival pathways results in decreased apoptosis, as inhibition of the PI3K/Akt pathway impairs cell survival. ${ }^{42} \mathrm{PI} 3 \mathrm{~K} /$ Akt signaling mediated aggrecan gene expression in NP cells, suggesting it function as a positive pathway in the IVD. ${ }^{43} \mathrm{FAK}$, a cytoplasmic tyrosine kinase involved in mechanotransduction, has been shown to regulate cell migration, proliferation, survival, and metabolism. ${ }^{44}$ The recognition of an extracellular matrix ligand by an integrin typically results in the clustering of the integrin in the cell membrane and activation of FAK, with subsequent regulation of focal adhesion dynamics and cell movement via the formation of focal adhesions at the submembranous region of the cell. ${ }^{45}$ In NP cells, FAK is activated by Ang-1 and FN to significantly promote cell adhesion. Furthermore, pFAK activates signaling pathways of mechanotransduction in NP cells, creating a potential binding site for the p85 receptor subunit of PI3K. It then activates the p110 catalytic subunit of PI3K, which leads to the phosphorylation of Akt, enhancing the viability of NP cells and reducing apoptosis. Ang-2 acts as a negative regulator in this process (Figure 6).

In summary, our data show that changes in the ratio of angiogenic factors Ang-2 and Ang-1 elicit NP cell apoptosis, likely initiating degeneration cascades. To our knowledge, our results demonstrate for the first time that NP cells express Ang-2 in an autocrine manner and respond to Ang/Tie2 signaling. Integrins respond to extracellular cues by modifying the avidity for Tie 2 and $\alpha 5 \beta 1$ signaling, enabling cross-talk between these pathways by acting at the level of the Tie2/ $\alpha 5 \beta 1$ complex. The strong correlation between the Ang-2/Ang-1 ratio and the degree of degeneration in IDD, observed in the present study, offers insights for IDD pathogenesis and indicates that blockade of Ang-2 function could be a potential therapeutic target to prevent NP cell loss in IVD.

Supplementary Information accompanies the paper on the Laboratory

Investigation website (http://www.laboratoryinvestigation.org)

\section{ACKNOWLEDGMENTS}

This work was supported by the National Natural Science Foundation of China (grant no. 81272025, 81541056).

\section{DISCLOSURE/CONFLICT OF INTEREST}

The authors declare no conflict of interest.

1. Sakai D, Andersson GBJ. Stem cell therapy for intervertebral disc regeneration: obstacles and solutions. Nat Rev Rheumatol 2015;11: 243-256.

2. Risbud MV, Shapiro IM. Role of cytokines in intervertebral disc degeneration: pain and disc content. Nat Rev Rheumatol 2014;10: 44-56.

3. Fontana G, See E, Pandit A. Current trends in biologics delivery to restore intervertebral disc anabolism. Adv Drug Deliv Rev 2015;84: 146-158.

4. Fiedler U, Augustin HG. Angiopoietins: a link between angiogenesis and inflammation. Trends Immunol 2006;27:552-558.

5. Huang $\mathrm{H}$, Bhat A, Woodnutt $\mathrm{G}$, et al. Targeting the ANGPT-TIE2 pathway in malignancy. Nat Rev Cancer 2010;10:575-585.

6. Kim H, Koh GY. Ang2, the instigator of inflammation. Blood 2011;118: 4767-4768.

7. Scholz A, Lang V, Henschler R, et al. Angiopoietin-2 promotes myeloid cell infiltration in a beta(2)-integrin-dependent manner. Blood 2011;118:5050-5059.

8. Fiedler U, Reiss $\mathrm{Y}$, Scharpfenecker $\mathrm{M}$, et al. Angiopoietin-2 sensitizes endothelial cells to TNF-alpha and has a crucial role in the induction of inflammation. Nat Med 2006;12:235-239.

9. Seguin CA, Pilliar RM, Roughley PJ, et al. Tumor necrosis factor-alpha modulates matrix production and catabolism in nucleus pulposus tissue. Spine (Phila Pa 1976) 2005;30:1940-1948.

10. Phillips KL, Cullen K, Chiverton N, et al. Potential roles of cytokines and chemokines in human intervertebral disc degeneration: interleukin-1 is a master regulator of catabolic processes. Osteoarthritis Cartilage 2015;23:1165-1177.

11. Wang J, Markova D, Anderson DG, et al. TNF-alpha and IL-1beta promote a disintegrin-like and metalloprotease with thrombospondin type I motif-5-mediated aggrecan degradation through syndecan-4 in intervertebral disc. J Biol Chem 2011;286:39738-39749.

12. Costa C, Engelman JA. The double life of p85. Cancer Cell 2014;26: 445-447. 
13. Sakai D, Nakamura $Y$, Nakai T, et al. Exhaustion of nucleus pulposus progenitor cells with ageing and degeneration of the intervertebral disc. Nat Commun 2012;3:1264.

14. Le Maitre CL, Frain J, Millward-Sadler J, et al. Altered integrin mechanotransduction in human nucleus pulposus cells derived from degenerated discs. Arthritis Rheum 2009;60:460-469.

15. Gilchrist CL, Chen J, Richardson WJ, et al. Functional integrin subunits regulating cell-matrix interactions in the intervertebral disc. J Orthop Res 2007;25:829-840.

16. Xia $M$, Zhu $Y$. Fibronectin fragment activation of ERK increasing integrin alpha(5) and beta(1) subunit expression to degenerate nucleus pulposus cells. J Orthop Res 2011;29:556-561.

17. Cascone I, Napione L, Maniero F, et al. Stable interaction between alpha5beta1 integrin and Tie2 tyrosine kinase receptor regulates endothelial cell response to Ang-1. J Cell Biol 2005;170:993-1004.

18. Pfirrmann CW, Metzdorf A, Zanetti $M$, et al. Magnetic resonance classification of lumbar intervertebral disc degeneration. Spine (Phila Pa 1976) 2001;26:1873-1878.

19. Wu X, Liu W, Duan $Z$, et al. The involvement of protease nexin-1 (PN1) in the pathogenesis of intervertebral disc (IVD) degeneration. Sci Rep 2016;6:30563.

20. Liu W, Zhang $Y$, Feng $X$, et al. Inhibition of microRNA-34a prevents IL-1 beta-induced extracellular matrix degradation in nucleus pulposus by increasing GDF5 expression. Exp Biol Med 2016;241:1924-1932.

21. Ding F, Shao ZW, Yang SH, et al. Role of mitochondrial pathway in compression-induced apoptosis of nucleus pulposus cells. Apoptosis 2012;17:579-590.

22. Priyadarshani $\mathrm{P}$, Li Y, Yao L. Advances in biological therapy for nucleus pulposus regeneration. Osteoarthritis Cartilage 2016;24:206-212.

23. Emanuel KS, Vergroesen PP, Peeters $M$, et al. Poroelastic behaviour of the degenerating human intervertebral disc: a ten-day study in a loaded disc culture system. Eur Cell Mater 2015;29:330-340; discussion 340-331.

24. Chan SC, Ferguson SJ, Gantenbein-Ritter B. The effects of dynamic loading on the intervertebral disc. Eur Spine J 2011;20:1796-1812.

25. Chan SC, Ferguson SJ, Wuertz K, et al. Biological response of the intervertebral disc to repetitive short-term cyclic torsion. Spine (Phila Pa 1976) 2011;36:2021-2030.

26. Pankov R. Fibronectin at a glance. J Cell Sci 2002;115:3861-3863.

27. Oegema Jr. TR, Johnson SL, Aguiar DJ, et al. Fibronectin and its fragments increase with degeneration in the human intervertebral disc. Spine (Phila Pa 1976) 2000;25:2742-2747.

28. Li J, Kawamura K, Cheng Y, et al. Activation of dormant ovarian follicles to generate mature eggs. Proc Natl Acad Sci USA 2010;107: 10280-10284.

29. Hu B, Jarzynka MJ, Guo $P$, et al. Angiopoietin 2 induces glioma cell invasion by stimulating matrix metalloprotease 2 expression through the alphavbeta1 integrin and focal adhesion kinase signaling pathway. Cancer Res 2006;66:775-783.
30. Horner A, Bord S, Kelsall AW, et al. Tie2 ligands angiopoietin-1 and angiopoietin-2 are coexpressed with vascular endothelial cell growth factor in growing human bone. Bone 2001;28:65-71.

31. Nagano $M$, Kimura $K$, Yamashita $T$, et al. Hypoxia responsive mesenchymal stem cells derived from human umbilical cord blood are effective for bone repair. Stem Cells Dev 2010;19: 1195-1210.

32. Imanishi $\mathrm{Y}, \mathrm{Hu}$ B, Jarzynka MJ, et al. Angiopoietin-2 stimulates breast cancer metastasis through the alpha(5)beta(1) integrin-mediated pathway. Cancer Res 2007;67:4254-4263.

33. Kurakawa T, Kakutani K, Morita $Y$, et al. Functional impact of integrin alpha5beta1 on the homeostasis of intervertebral discs: a study of mechanotransduction pathways using a novel dynamic loading organ culture system. Spine J 2015;15:417-426.

34. Felcht $M$, Luck $R$, Schering $A$, et al. Angiopoietin-2 differentially regulates angiogenesis through TIE2 and integrin signaling. J Clin Invest 2012;122:1991-2005.

35. Lee HS, Oh SJ, Lee $\mathrm{KH}$, et al. Gln-362 of angiopoietin-2 mediates migration of tumor and endothelial cells through association with alpha5beta1 integrin. J Biol Chem 2014;289:31330-31340.

36. Park SW, Yun $\mathrm{JH}, \mathrm{Kim} \mathrm{JH}$, et al. Angiopoietin 2 induces pericyte apoptosis via alpha3beta1 integrin signaling in diabetic retinopathy. Diabetes 2014;63:3057-3068.

37. Yancopoulos GD, Davis S, Gale NW, et al. Vascular-specific growth factors and blood vessel formation. Nature 2000;407:242-248.

38. Maisonpierre PC. Angiopoietin-2, a natural antagonist for Tie2 that disrupts in vivo angiogenesis. Science 1997;277:55-60.

39. Ruoslahti E, Reed JC. Anchorage dependence, integrins, and apoptosis. Cell 1994;77:477-478.

40. Greg Anderson D, Li X, Tannoury T, et al. A fibronectin fragment stimulates intervertebral disc degeneration in vivo. Spine (Phila Pa 1976) 2003;28:2338-2345.

41. Anderson DG, Li X, Balian G. A fibronectin fragment alters the metabolism by rabbit intervertebral disc cells in vitro. Spine (Phila Pa 1976) 2005;30:1242-1246.

42. Risbud MV, Fertala J, Vresilovic EJ, et al. Nucleus pulposus cells upregulate PI3K/Akt and MEK/ERK signaling pathways under hypoxic conditions and resist apoptosis induced by serum withdrawal. Spine (Phila Pa 1976) 2005;30:882-889.

43. Cheng CC, Uchiyama Y, Hiyama A, et al. PI3K/AKT regulates aggrecan gene expression by modulating Sox9 expression and activity in nucleus pulposus cells of the intervertebral disc. J Cell Physiol 2009;221:668-676.

44. Dasari VR, Kaur K, Velpula KK, et al. Downregulation of focal adhesion kinase (FAK) by cord blood stem cells inhibits angiogenesis in glioblastoma. Aging 2010;2:791-803.

45. Parsons JT, Martin KH, Slack JK, et al. Focal adhesion kinase: a regulator of focal adhesion dynamics and cell movement. Oncogene 2000;19: 5606-5613. 